\title{
Kinetic Analysis of the Pyrolysis of Apricot Stone and its Main Components via Distributed Activation Energy Mode
}

Huanhuan Ma, Yimeng Zhang, Liangcai Wang, Zhengxiang Zhu, Yu Chen, Huilin Wang, Congjing Deng, * and Jianbin Zhou *

The kinetics of pyrolysis of apricot stone and its main components, i.e., lignin, cellulose, and hemicellulose, were investigated via distributed activation energy mode. Experiments were done in a thermogravimetric analyzer at heating rates of $10,20,30$, and $40 \mathrm{~K} \cdot \mathrm{min}^{-1}$ under nitrogen. The activation energy distribution peaks for the apricot stone, lignin, cellulose, and hemicellulose were centered at 246, 318, 364, and $170 \mathrm{~kJ} \cdot \mathrm{mol}^{-1}$, respectively. The activation energy distribution for the apricot stone slightly changed; lignin exhibited the widest distribution; and cellulose exhibited the highest activation energy at a conversion degree $(\alpha)$ of less than 0.75 . At low pyrolysis temperatures $(400 \mathrm{~K}$ to $600 \mathrm{~K})$, the pyrolysis of hemicellulose was the main pyrolysis reaction. The apparent activation energy for the apricot stone mainly depended on the pyrolysis of hemicellulose and a small amount of lignin, and the activation energy was low in the early stage of pyrolysis. With the continuous increase in the pyrolysis temperatures $(600 \mathrm{~K}$ to $660 \mathrm{~K})$, the thermal weight loss of cellulose and lignin was intense. The apparent activation energy for the apricot stone mainly resulted from the pyrolysis of cellulose and lignin, and a higher activation energy was observed in the later stage of pyrolysis.

Keywords: Apricot stone; Pyrolysis; Kinetics analysis; Distributed activation energy mode; Conversion degree

Contact information: a: Materials Science and Engineering College, Nanjing Forestry University, Nanjing

210037, China; b: Planning and Design Institute of Forest Products Industry, State Forestry and Grassland Administration, Beijing 100010, China;

*Corresponding authors: 15801407563@163.com; zhoujianbin@njfu.edu.cn

\section{INTRODUCTION}

With the gradual substitution of conventional fossils, increased importance has been placed on the production of carbon-neutral, low-emission fuels from biomass renewable resources, which is a significant feedstock for the renewable production of fuels and chemicals (Gaurav et al. 2017; Akhtar et al. 2018). As the only renewable carbonaceous resource, biomass demonstrates the potential to produce heat, electricity, fuel, chemicals, and other products, and the utilization of biomass resources has attracted increasing attention (Tan et al. 2019; Usman et al. 2019).

Thermochemical conversion technology is regarded as a key technology that enables the conversion of biomass into high value-added chemicals and fuels. The main thermochemical processes include pyrolysis (Xu et al. 2019), combustion (Dorez et al. 2014), gasification (Li et al. 2018), liquefaction (Wang et al. 2018), and carbonization (Li et al. 2008). Among these thermochemical pathways, pyrolysis, which involves the thermal decomposition of organics in the absence of oxygen, has been extensively developed as a promising platform to produce fuels and chemicals from various types of biomass (Cai et 
al. 2014). Lignocellulosic biomass is mainly composed of lignin, cellulose, and hemicellulose (Wang et al. 2016c). Lignin is typically composed of methoxylated phenylpropane units, which are polymerized by monolignols ( $\mathrm{p}$-hydroxyphenyl, guaiacyl, and syringyl units), and different ether bonds and carbon-carbon bonds (Jiang et al. 2010). In contrast to lignin, cellulose and hemicellulose exhibit relatively simple structures, only containing sugar units (such as pentoses and hexoses) and glycosidic bonds (Shen et al. 2010a).

Due to the complexity of the biomass pyrolysis reaction, it is extremely difficult to describe the entire reaction process and its interaction from the perspective of a microscopic process (Ranzi et al. 2008; Chen et al. 2014). To obtain relatively simple models to guide the process design, the laws of pyrolysis are typically explained by epigenetic characteristics. Pyrolysis kinetics is an important method used by graduate students to examine the pyrolysis characteristics and mechanism of solid substances such as biomass (Hu et al. 2016), coal (Bhagavatula et al. 2016; Coimbra et al. 2019), and other solid combustibles (Bartocci et al. 2019; Song et al. 2019). Thermal analysis serves as a high-precision analysis method for examining reaction kinetics, reflecting the rules and characteristics of pyrolysis from the perspective of solid biofuels (Ma et al. 2015; Carvalho and Tannous 2017; Zhou et al. 2018). The Kissinger-Akahira-Sunose method (Slopiecka et al. 2012; Ali et al. 2018), Flynn-Wall-Ozawa method ( Damartzis et al. 2011; Carvalho and Tannous 2017), Kissinger method (Viottoa et al. 2018), and distributed activation energy mode (DAEM) method (Zhang et al. 2014; De Caprariis et al. 2015) are widely employed for the kinetics analysis of the pyrolysis of biomass.

Apricot (Prunus armeniaca L.) is an important econo-ecological tree species in semi-arid areas of northern China, and the deep processing of its fruits affords its stone as the waste product, with an annual output of 400,000 to 500,000 tons. Apricot stone is an important raw material for preparing activated carbon (Jia et al. 2013; Yang et al. 2015; Marzbali et al. 2016), which is mainly composed of lignin, cellulose, hemicellulose, and other organic macromolecular components (Ali et al. 2011; Corbett et al. 2015). The chemical structures of these three components are different. The pyrolysis of apricot stone can be considered as the comprehensive performance of the pyrolysis reactions of the three components, and the pyrolysis process is relatively complex (Yang et al. 2007; Demiral and $\mathrm{Kul} 2014$ ). Therefore, in the basic research of biomass pyrolysis, it is crucial to conduct in-depth research on the pyrolysis mechanism of raw materials and major components (Yan et al. 2019). Many previous studies on biomass components have been based on different model compounds, lignin, cellulose and hemicellulose isolated from biomass are closer to the natural form. In this study, the heat reaction of an apricot stone, as well as its components of lignin, cellulose, and hemicellulose, were examined by the DAEM, and the relationship between the pyrolysis activation energy and conversion degree was discussed. The results provided basic data and a theoretical basis for the efficient utilization of apricot stone biomass and research of the thermal reaction mechanism.

\section{EXPERIMENTAL}

\section{Materials}

Apricot stone raw material

Apricot stone was collected from the Hebei Province (China), milled, and screened to obtain a particle size of 100-mesh. Proximate analysis was tested according to ASTM 
D1102-84 (2013), ASTM E872-82 (2013), ASTM E871-82 (2013). The ultimate analysis was performed under the $\mathrm{C}, \mathrm{H}, \mathrm{N}$, and $\mathrm{S}$ models using an elemental analyzer (Vario EL III; Elementar, Hanau, Germany), and oxygen was estimated by the difference method: $\mathrm{O}(\%)$ $=100 \%-\mathrm{C}(\%)-\mathrm{H}(\%)-\mathrm{N}(\%)-\mathrm{S}(\%)-$ Ash $(\%)$. Table 1 summarizes the results obtained.

Table 1. Proximate and Ultimate Analyses of the Apricot Stone (Dry Basis)

\begin{tabular}{|c|c|c|c|}
\hline \multicolumn{2}{|c|}{ Proximate Analysis (wt\%) } & \multicolumn{2}{c|}{ Ultimate Analysis (wt\%) } \\
\hline Fixed carbon & 17.41 & Carbon $(\mathrm{C})$ & 50.66 \\
\hline Ash & 0.64 & Nitrogen $(\mathrm{N})$ & 0.12 \\
\hline Volatile matter & 81.85 & Hydrogen $(\mathrm{H})$ & 5.45 \\
\hline Moisture & 7.76 & Sulfur (S) & 0.08 \\
\hline & & Oxygen (O) & 43.05 \\
\hline
\end{tabular}

The pretreated raw material of the apricot stone was extracted using a benzeneethanol mixture $(2 / 1, \mathrm{v} / \mathrm{v})$ for $6 \mathrm{~h}$. Next, this extracted material was subjected to vacuum drying in an oven at $50{ }^{\circ} \mathrm{C}$ for $12 \mathrm{~h}$, followed by grinding until all of the raw material was screened through a 140-mesh to extract lignin, cellulose, and hemicellulose.

\section{Extraction of lignin}

A $72 \%$ sulfuric acid solution was added to the pretreated raw material and it was stirred sufficiently at $20^{\circ} \mathrm{C}$ for $2.5 \mathrm{~h}$. The solution was filtered, and the filtrate liquor was boiled and subjected to reflux conditions with distilled water for $4 \mathrm{~h}$. The liquor was left to stand for $30 \mathrm{~min}$ before filtering, and the filtered residue was repeatedly washed with hot water until a neutral $\mathrm{pH}$ was attained. The sample obtained after drying was the apricot stone lignin according to TAPPI T222 (2002), also referred to as Klason lignin $(30.42 \%$ yield).

\section{Extraction of cellulose}

First, $260 \mathrm{~mL}$ of distilled water, $3 \mathrm{~g}$ of sodium chlorite, and $2 \mathrm{~mL}$ of acetic acid were added into $8 \mathrm{~g}$ of the pretreated raw material and subjected to oscillation twice at 75 ${ }^{\circ} \mathrm{C}$ for $1 \mathrm{~h}$. After the reaction was completed, the reaction was immediately placed in ice water, followed by filtration. Then, the residue was washed with distilled water until a neutral $\mathrm{pH}$ was attained. Next, the residue was washed thrice with acetone, air-dried in a fume hood, and dried in a drying oven at $50{ }^{\circ} \mathrm{C}$ for $12 \mathrm{~h}$. The sample obtained was apricot stone holocellulose.

First, $24 \mathrm{wt} \%$ of $\mathrm{KOH}$ and $2 \mathrm{wt} \%$ of $\mathrm{H}_{3} \mathrm{BO}_{3}$ at a solid-liquid ratio of 1:20 were added into $10 \mathrm{~g}$ of holocellulose, followed by vibration in a constant-temperature water bath at $20{ }^{\circ} \mathrm{C}$ for $2 \mathrm{~h}$. After the reaction was completed, it was filtered, and the residue was washed with distilled water until a neutral $\mathrm{pH}$ was attained (Stefanidis et al. 2014). The sample obtained after freeze-drying the residue was apricot stone cellulose (24.6\% yield).

\section{Extraction of hemicellulose}

First, a $17 \mathrm{wt} \% \mathrm{NaOH}$ solution was used to extract apricot stone holocellulose at $20{ }^{\circ} \mathrm{C}$ for $2 \mathrm{~h}$ before filtration. The filtered liquor was neutralized by $6 \mathrm{~mol} \cdot \mathrm{L}^{-1}$ acetic acid until its $\mathrm{pH}$ was 5.5, followed by the addition of a $95 \mathrm{wt} \%$ ethanol solution to allow for the complete precipitation of hemicellulose, followed by centrifugation, filtration, and freeze- 
drying (Stefanidis et al. 2014). The sample obtained after freeze-drying the residue was apricot stone hemicellulose (29.4\% yield).

\section{Methods}

The thermal properties of the apricot stone and its main components were examined using a thermal gravimetric analyzer (TGA Q5000; TA Instruments, New Castle, DE, USA). All samples were individually heated from room temperature to $1073 \mathrm{~K}$ at different heating rates of $10,20,30$, and $40 \mathrm{~K} \cdot \mathrm{min}^{-1}$. The weight of each experimental sample was $15 \mathrm{mg}$, the carrier gas was high-purity nitrogen, and the flow rate was $70 \mathrm{~mL} \cdot \mathrm{min}^{-1}$.

\section{Kinetic Studies}

The DAEM was first proposed in 1942 (Vand 1943), and was gradually applied for the pyrolysis of fossil fuels. The DAEM is applied based on the hypothesis of an infinite parallel reaction and activation energy distribution. It has been widely applied to the kinetics analysis of some complex reaction systems (Lin et al. 2018; Ren et al. 2018). Biomass pyrolysis comprises multiple reactions. Let the total volatilization of the $\mathrm{i}$ of the reaction be $V_{\mathrm{i}}{ }^{*}$ and the volatilization amount up to time $t$ be $V_{\mathrm{i}}$. According to the two assumptions of the DAEM model, the kinetics equation of reaction $i$ is expressed as follows, where $k$ represents kinetic constant $\left(\mathrm{mol} \cdot \mathrm{s}^{-1}\right), A$ represents the pre-exponential factor, $R$ represents universal gas constant $\left(8.314 \mathrm{~J} \cdot \mathrm{mol}^{-1} \cdot \mathrm{K}^{-1}\right)$, and $T$ is absolute temperature $(\mathrm{K})$ :

$$
\begin{aligned}
\frac{\mathrm{d} V_{i}}{\mathrm{~d} t} & =k_{i}\left(V_{i}^{*}-V_{i}\right) \\
k_{i} & =A_{i} e^{-E_{i} / R T}
\end{aligned}
$$

By integrating both sides of the transformation Eq. 1,

$$
\frac{V_{i}}{V_{i}^{*}}=\exp \left[-\int_{0}^{1} A_{i} e^{-\frac{E_{i}}{R T}}\right]
$$

when the reaction number of the system is 1 , the above model is a first-order model reaction. In fact, the composition of biomass, such as an apricot stone, is extremely complex, and many reactions are possible during pyrolysis. The corresponding reaction quantities in the DAEM model can be expressed by differential calculus; namely, $\mathrm{d}_{\mathrm{V}}$ replaces $V_{\mathrm{i}}, \mathrm{d} V_{*}$ replaces $V_{\mathrm{i}}^{*}$, and $\mathrm{d} V^{*}$ depends on the activation energy distribution:

$$
d V^{*}=V^{*} g(E) \mathrm{d} E
$$

According to the above equation, the distributed activation energy function satisfies

$$
\int_{0}^{\infty} g(E) \mathrm{d} E=0
$$

The differential transformation of Eq. 4 is carried out, and Eqs. 6 and 7 are as follows:

$$
\begin{aligned}
& \mathrm{d} V=d V^{*}\left(1-e^{-\int_{0}^{t} A_{i} e^{-\frac{E_{i}}{R T}}}\right) \\
& \frac{V_{i}}{V_{i}^{*}}=\int_{0}^{\infty}\left(1-e^{-\int_{0}^{t} A_{i} e^{-\frac{E_{i}}{R T}}}\right) g(E) \mathrm{d} E
\end{aligned}
$$


Non-isothermal thermal analysis is adopted, and Eq. 8 is characterized by the mass fraction of the residual matter analyzed by TGA and the mass fraction of the residual matter at the end of pyrolysis, in which $w$ represents the initial mass (mass $\%$ ), and $w_{\mathrm{f}}$ represents the final residual mass (mass\%):

$$
\frac{V^{*}-V}{V^{*}}=\frac{w-w_{f}}{1-w_{f}}
$$

The Miura integral method was employed to examine the activation energy distribution characteristics of the apricot stone, lignin, cellulose, and hemicellulose. According to the Miura integral principle, the Arrhenius equation is expressed as follows:

$$
\ln \left(\frac{\beta}{T^{2}}\right)=\ln \left(\frac{k R}{E}\right)-\ln \left\{-\ln \left(1-\frac{V_{i}}{V_{i}^{*}}\right)\right\}-\frac{E}{R T}
$$

The TGA method was employed to measure the relationship between the conversion degree $\alpha\left(V / V^{*}\right)$ and $T$ at different heating rates $\beta$ (i.e., 10, 20, 30, and 40 $\left.\mathrm{K} \cdot \mathrm{min}^{-1}\right)$, and, by using the TGA curve data, $\ln \left(\beta / T^{2}\right)$ was plotted as a function of $1 / T$. The Arrhenius line was plotted using the same $\alpha$ value at different heating rates through the Origin software (Origin, OriginLab, 8.5, Massachusetts, USA); according to the slope of the line, the activation energy $E$ under the conversion rate can be calculated (Wang et al. 2012).

\section{RESULTS AND DISCUSSION}

\section{TGA of the Apricot Stone}

The TG and DTG curves of the apricot stone exhibited the same change trends at different heating rates (Fig. 1). The main pyrolysis temperature range was $475 \mathrm{~K}$ to $775 \mathrm{~K}$, and the weight loss was $\sim 76 \%$. The heating rates were $10,20,30$, and $40 \mathrm{~K} \cdot \mathrm{min}^{-1}$ and the pyrolysis temperature was $1075 \mathrm{~K}$; the pyrolysis yields of solid products were $18.4 \%$, $18.2 \%, 18.2 \%$, and $17.1 \%$, respectively.

With the increase in the heating rate, the TG curves shifted to the right, indicating that instantaneous pyrolysis weightlessness decreased at the same pyrolysis temperature. It was mainly affected by the heat and mass transfer. From the DTG curves of the apricot stone, the pyrolysis interval consisted of two peaks. The temperatures associated with the first peak were $551.5 \mathrm{~K}, 564.2 \mathrm{~K}, 571.1 \mathrm{~K}$, and $573.1 \mathrm{~K}$, and their corresponding weight loss rates were $-5.26 \mathrm{wt} \% \cdot \mathrm{min}^{-1},-10.69 \mathrm{wt} \% \cdot \mathrm{min}^{-1},-15.85 \mathrm{wt} \% \cdot \mathrm{min}^{-1}$, and -20.22 $\mathrm{wt} \% \cdot \mathrm{min}^{-1}$ at heating rates of $10 \mathrm{~K} \cdot \mathrm{min}^{-1}, 20 \mathrm{~K} \cdot \mathrm{min}^{-1}, 30 \mathrm{~K} \cdot \mathrm{min}^{-1}$, and $40 \mathrm{~K} \cdot \mathrm{min}^{-1}$, respectively. The temperatures associated with the second peak were $620.3 \mathrm{~K}, 630.1 \mathrm{~K}$, $635.5 \mathrm{~K}$, and $638.1 \mathrm{~K}$, respectively, and their corresponding weight loss rates were -7.50 $\mathrm{wt} \% \cdot \mathrm{min}^{-1},-14.57 \mathrm{wt} \% \cdot \mathrm{min}^{-1},-21.54 \mathrm{wt} \% \cdot \mathrm{min}^{-1}$, and $-27.76 \mathrm{wt} \% \cdot \mathrm{min}^{-1}$ at heating rates of $10 \mathrm{~K} \cdot \mathrm{min}^{-1}, 20 \mathrm{~K} \cdot \mathrm{min}^{-1}, 30 \mathrm{~K} \cdot \mathrm{min}^{-1}$, and $40 \mathrm{~K} \cdot \mathrm{min}^{-1}$, respectively.

As the heating rate increased, the temperature of the two positions of peaks increased, and the maximum weight loss rate increased dramatically (Ahmad et al. 2018; Saikia et al. 2018). 

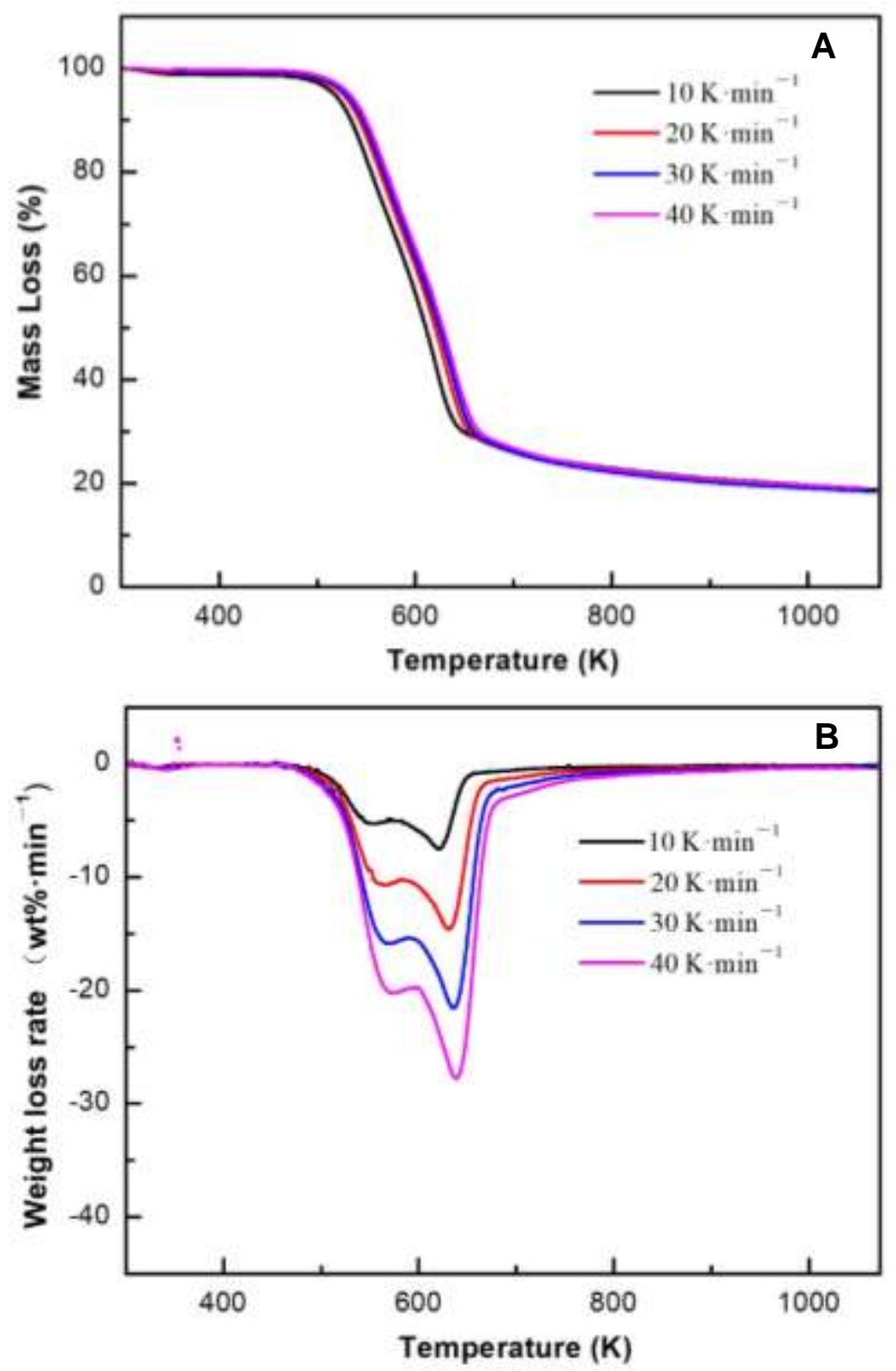

Fig. 1. TG (a) and DTG (b) curves of the apricot stone

\section{TGA of Apricot Stone Lignin}

The TG and DTG curves of the apricot stone lignin exhibited the same change trends at different heating rates (Fig. 2). The main pyrolysis temperature range was relatively wide ( $500 \mathrm{~K}$ to $1000 \mathrm{~K}$ ), and the weight loss was $60 \%$ to $66 \%$. The heating rates were $10 \mathrm{~K} \cdot \mathrm{min}^{-1}, 20 \mathrm{~K} \cdot \mathrm{min}^{-1}, 30 \mathrm{~K} \cdot \mathrm{min}^{-1}$, and $40 \mathrm{~K} \cdot \mathrm{min}^{-1}$; the pyrolysis temperature was $1075 \mathrm{~K}$, and the pyrolysis yields of solid products were $38.5 \%$, 37.0\%, 35.7\%, and 32.2\%, respectively. The peak temperatures corresponding to the DTG curve moved to the hightemperature direction; the maximum weightlessness temperatures were $624.9 \mathrm{~K}, 641.5 \mathrm{~K}$, $654.2 \mathrm{~K}$, and $661.1 \mathrm{~K}$, and the maximum weightlessness rates were $-5.33 \mathrm{wt} \% \cdot \mathrm{min}^{-1}$, $-9.59 \mathrm{wt} \% \cdot \mathrm{min}^{-1},-14.18 \mathrm{wt} \% \cdot \mathrm{min}^{-1}$, and $-20.75 \mathrm{wt} \% \cdot \mathrm{min}^{-1}$, respectively. The maximum weightlessness temperatures of the apricot stone lignin were greater than those of the 
apricot stone, while the maximum weightlessness rates were lower (Shen et al. 2010b; Stefanidis et al. 2014).
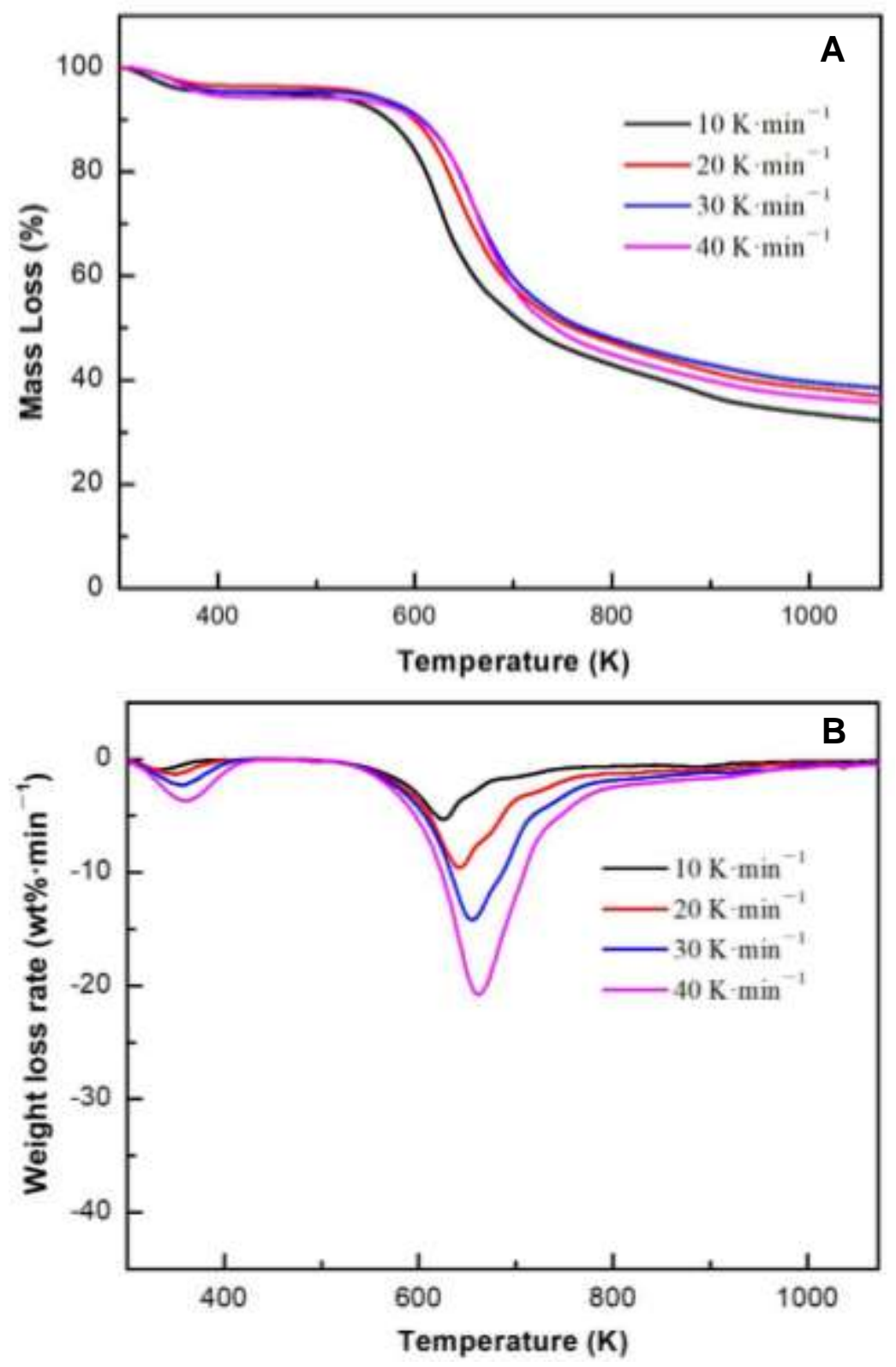

Fig. 2. TG (a) and DTG (b) curves of the apricot stone lignin

\section{TGA of Apricot Stone Cellulose}

A narrow pyrolysis temperature range for apricot stone cellulose (520 K to $775 \mathrm{~K}$ ) was observed (Fig. 3). With the increase in the heating rate, due to the effect of heat-transfer hysteresis, the positions of the TG curve and maximum weight loss rate shifted to the hightemperature side. With the increase in the heating rate from $10 \mathrm{~K} \cdot \mathrm{min}^{-1}$ to $40 \mathrm{~K} \cdot \mathrm{min}^{-1}$, the maximum weight loss temperature gradually increased from $623.17 \mathrm{~K}$ to $648.39 \mathrm{~K}$, and the weight loss rate increased from $-14.04 \mathrm{wt} \% \cdot \mathrm{min}^{-1}$ to $-41.11 \mathrm{wt} \% \cdot \mathrm{min}^{-1}$. The macromolecule chain of apricot stone cellulose was neat, which meant that the polymer chains break first (Soni et al. 2015). The dissociation energy of glycosides that were 
between the adjacent ring bonds was similar, and as the initial pyrolysis temperature of weightlessness gradually increased, the DTG curve exhibits sharp weightlessness peaks (Burhenne et al. 2013).
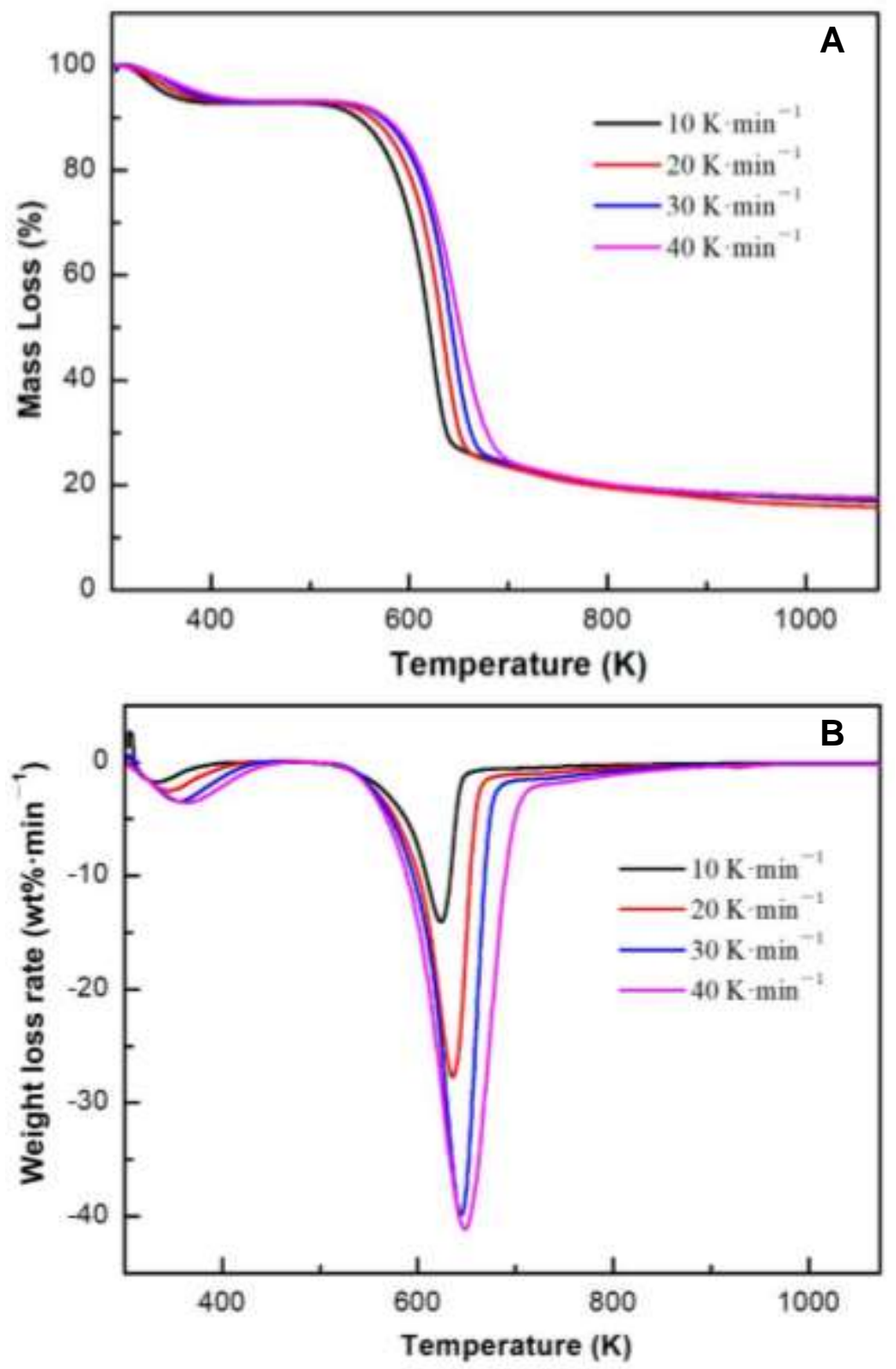

Fig. 3. TG (a) and DTG (b) curves of apricot stone cellulose

\section{TGA of Apricot Stone Hemicellulose}

The pyrolysis temperature range of apricot stone hemicellulose was $475 \mathrm{~K}$ to 700 $\mathrm{K}$ (Fig. 4). With the increase in the heating rate, the starting and ending temperatures of each stage slightly shifted to the high-temperature side, and the main reaction interval also slightly increased because of the presence of side chains in the molecular structure of apricot stone hemicellulose, which were easily broken at lower temperature. After the decomposition of the side chain, the main reaction tended to be polymer-chain depolymerization and intramolecular dehydration condensation. The heating rates were 10 
$\mathrm{K} \cdot \mathrm{min}^{-1}, 20 \mathrm{~K} \cdot \mathrm{min}^{-1}, 30 \mathrm{~K} \cdot \mathrm{min}^{-1}$, and $40 \mathrm{~K} \cdot \mathrm{min}^{-1}$, and the weight loss rate extremum positions were $568.7 \mathrm{~K}, 581.7 \mathrm{~K}, 587.9 \mathrm{~K}$, and $592.6 \mathrm{~K}$, respectively, in the DTG curve. These temperatures were the minimum temperatures of the maximum weight loss temperature for the pyrolysis of apricot stone and its components in different heating rates, suggesting that apricot stone hemicellulose was the most unstable component (Wang et al. 2016b).
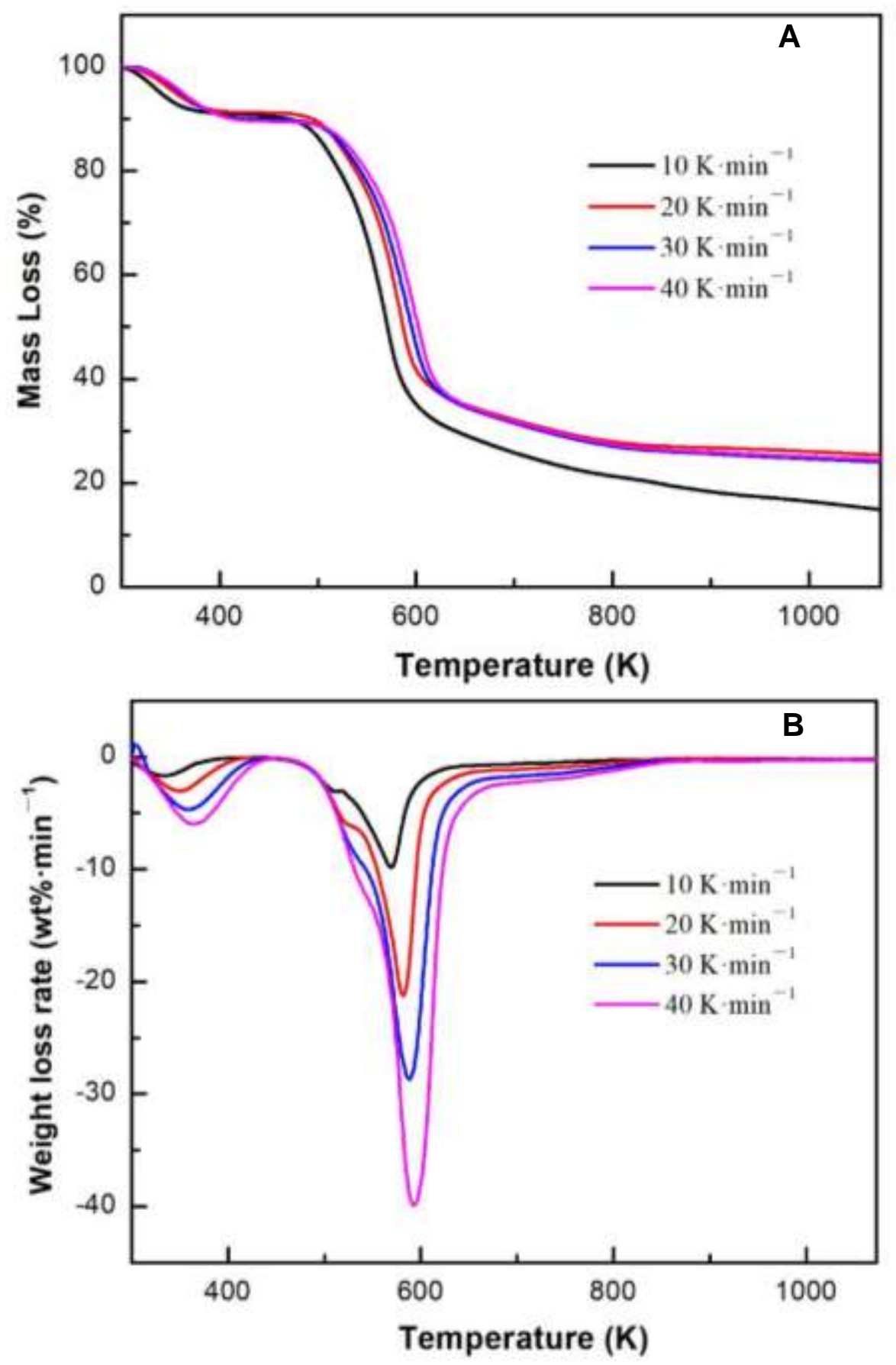

Fig. 4. TG (a) and DTG (b) curves of apricot stone hemicelluloses 


\section{Kinetics Analysis}

Arrhenius line

The DAEM method was employed to understand the relationship between $T$ and $\alpha$ at different temperature increase rates during pyrolysis. According to the TG curve data, $\ln$ $\left(\beta / T^{2}\right)$ was plotted as a function of $1 / T$, and the Arrhenius line was fitted with the same $\alpha$ value at different heating rates. According to the slope of the line fitting equation, the activation energy $(E)$ that corresponded to the conversion rate was obtained. Figure 5 shows the Arrhenius plots of the apricot stone, lignin, cellulose, and hemicellulose at heating rates of $10 \mathrm{~K} \cdot \mathrm{min}^{-1}, 20 \mathrm{~K} \cdot \mathrm{min}^{-1}, 30 \mathrm{~K} \cdot \mathrm{min}^{-1}$, and $40 \mathrm{~K} \cdot \mathrm{min}^{-1}$ as a function of $\alpha$.
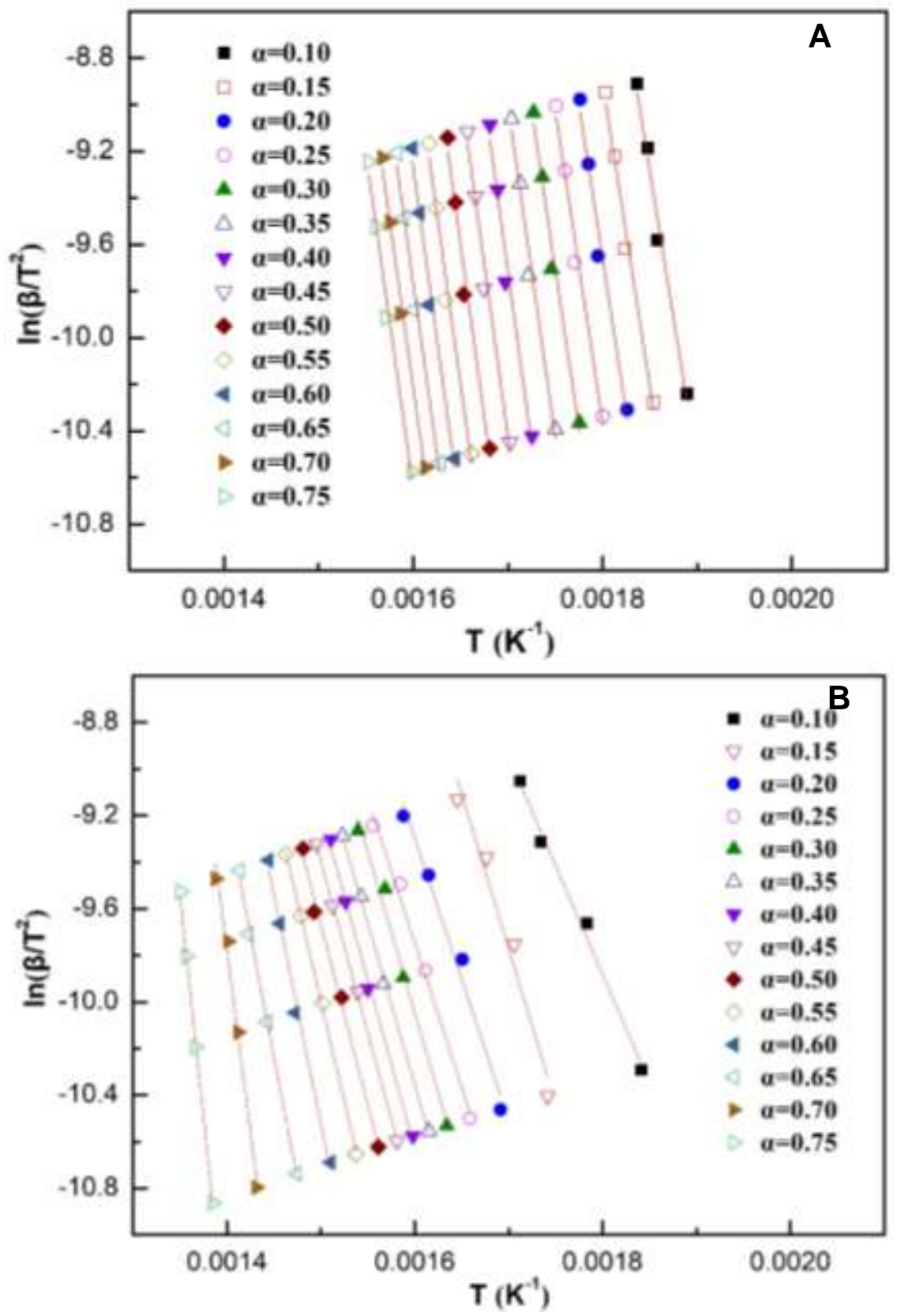

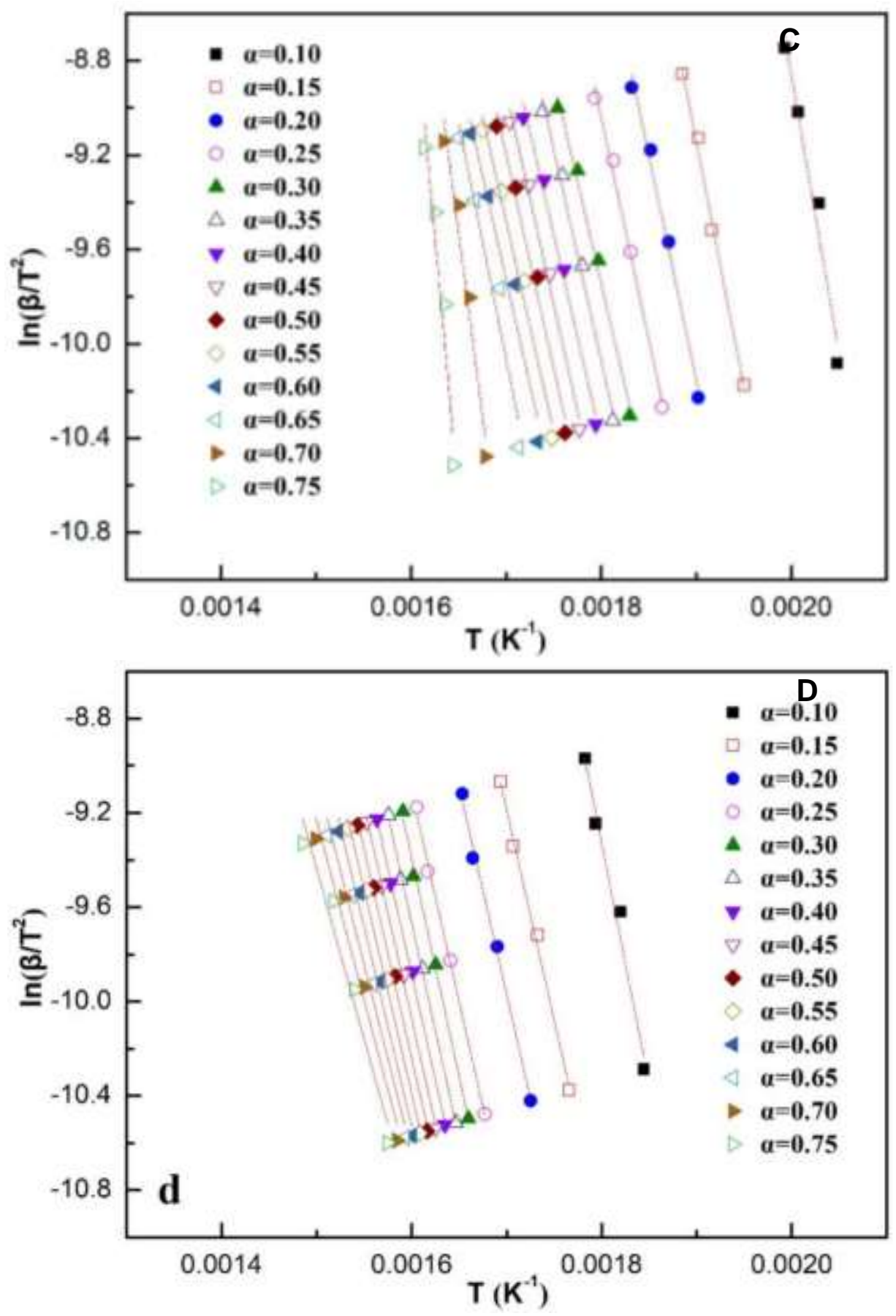

Fig. 5. Arrhenius plots of $\ln \left(\beta / T^{2}\right)$ as a function of $1 / T$ at a selected $\alpha$ for the apricot stone (a), lignin (b), cellulose (c), and hemicellulose (d)

The $\alpha$ values used for kinetics analysis were in the range of 0.10 to 0.75 . Table 2 summarizes the kinetics parameters for the pyrolysis decomposition of apricot stone, lignin, cellulose, and hemicellulose at distinct heating rates. The $\mathrm{R}^{2}$ data for various pyrolysis decomposition were in the range of 0.9080 to 0.9992 , indicating that the mechanism models selected for kinetics analysis were reliable. 
Table 2. Slope and Correlation Coefficient $R^{2}$ Obtained by the DEAM of the Apricot Stone, Lignin, Cellulose, and Hemicellulose

\begin{tabular}{|c|c|c|c|c|c|c|c|}
\hline Sample & $\alpha$ & Slope & $\mathbf{R}^{2}$ & Sample & $\alpha$ & Slope & $\mathbf{R}^{2}$ \\
\hline \multirow{14}{*}{$\begin{array}{l}\text { Apricot } \\
\text { stone }\end{array}$} & 0.10 & -25188.08 & 0.9781 & \multirow{14}{*}{$\begin{array}{l}\text { Apricot stone } \\
\text { lignin }\end{array}$} & 0.10 & -9314.56 & 0.9882 \\
\hline & 0.15 & -26107.14 & 0.9772 & & 0.15 & -13299.47 & 0.9535 \\
\hline & 0.20 & -26498.21 & 0.9720 & & 0.20 & -12098.98 & 0.9751 \\
\hline & 0.25 & -26737.91 & 0.9747 & & 0.25 & -12394.21 & 0.9871 \\
\hline & 0.30 & -27274.99 & 0.9744 & & 0.30 & -13783.37 & 0.9802 \\
\hline & 0.35 & -28568.38 & 0.9741 & & 0.35 & -13822.36 & 0.9981 \\
\hline & 0.40 & -29571.23 & 0.9652 & & 0.40 & -14439.05 & 0.9947 \\
\hline & 0.45 & -29474.40 & 0.9729 & & 0.45 & -14766.21 & 0.9992 \\
\hline & 0.50 & -29560.85 & 0.9707 & & 0.50 & -15477.92 & 0.9922 \\
\hline & 0.55 & -29199.44 & 0.9722 & & 0.55 & -17190.33 & 0.9991 \\
\hline & 0.60 & -29379.67 & 0.9768 & & 0.60 & -19497.03 & 0.9902 \\
\hline & 0.65 & -29141.24 & 0.9825 & & 0.65 & -20933.2 & 0.9963 \\
\hline & 0.70 & -28837.70 & 0.9863 & & 0.70 & -31224.58 & 0.9821 \\
\hline & 0.75 & -28699.90 & 0.9826 & & 0.75 & -38189.44 & 0.9987 \\
\hline Sample & $\alpha$ & Slope & $\mathbf{R}^{2}$ & Sample & $\alpha$ & Slope & $\mathbf{R}^{2}$ \\
\hline \multirow{14}{*}{$\begin{array}{l}\text { Apricot } \\
\text { stone } \\
\text { cellulose }\end{array}$} & 0.10 & -23578.29 & 0.9548 & \multirow{14}{*}{$\begin{array}{l}\text { Apricot stone } \\
\text { hemicellulose }\end{array}$} & 0.10 & -20437.28 & 0.9746 \\
\hline & 0.15 & -20697.97 & 0.9914 & & 0.15 & -17847.21 & 0.9936 \\
\hline & 0.20 & -19085.91 & 0.9861 & & 0.20 & -17657.22 & 0.9929 \\
\hline & 0.25 & -18814.12 & 0.9889 & & 0.25 & -17826.77 & 0.9958 \\
\hline & 0.30 & -17354.84 & 0.9868 & & 0.30 & -18523.23 & 0.9955 \\
\hline & 0.35 & -17910.25 & 0.9854 & & 0.35 & -18261.12 & 0.9978 \\
\hline & 0.40 & -17364.68 & 0.9839 & & 0.40 & -17954.34 & 0.9981 \\
\hline & 0.45 & -17984.86 & 0.9849 & & 0.45 & -17989.85 & 0.9968 \\
\hline & 0.50 & -18094.87 & 0.9772 & & 0.50 & -17689.76 & 0.9956 \\
\hline & 0.55 & -17860.44 & 0.9750 & & 0.55 & -17331.22 & 0.9928 \\
\hline & 0.60 & -17842.76 & 0.9486 & & 0.60 & -16922.87 & 0.9843 \\
\hline & 0.65 & -20008.26 & 0.9352 & & 0.65 & -15916.19 & 0.9735 \\
\hline & 0.70 & -30778.61 & 0.9461 & & 0.70 & -15229.85 & 0.9531 \\
\hline & 0.75 & -43828.83 & 0.9080 & & 0.75 & -14458.78 & 0.9384 \\
\hline
\end{tabular}

\section{Pyrolysis Activation Energy}

In the DAEM, the activation energy values obtained for the apricot stone, lignin, cellulose, and hemicellulose were a function of $\alpha$ (Fig. 6). From the change in the activation energy for the pyrolysis of the apricot stone, the activation energy did not linearly increase with the progress of pyrolysis, but it increased from $209 \mathrm{~kJ} \cdot \mathrm{mol}^{-1}$ to $245 \mathrm{~kJ} \cdot \mathrm{mol}^{-1}$, representing an increase to a stable change trend (Shen et al. 2011). At an $\alpha$ value less than 0.40 , as $\alpha$ increased, the activation energy increased from $209 \mathrm{~kJ} \cdot \mathrm{mol}^{-1}$ to the maximum of $245.9 \mathrm{~kJ} \cdot \mathrm{mol}^{-1}$. When $\alpha$ was between 0.40 and $0.60, E$ slightly fluctuated up and down near $245 \mathrm{~kJ} \cdot \mathrm{mol}^{-1}$. At an $\alpha$ greater than 0.6 , the activation energy slightly decreased.

From Fig. 6, the activation energy for the pyrolysis of apricot stone lignin gradually increased with the progress of the reaction. At an $\alpha$ less than 0.55, the activation energy increased from $77.4 \mathrm{~kJ} \cdot \mathrm{mol}^{-1}$ to $142.9 \mathrm{~kJ} \cdot \mathrm{mol}^{-1}$ with the increase of $\alpha$. At this stage, the activation energy for apricot stone lignin was less than those for the apricot stone and other components. At an $\alpha$ greater than 0.6 , the activation energy suddenly increased, reaching $317.5 \mathrm{~kJ} \cdot \mathrm{mol}^{-1}$ at an $\alpha$ of 0.75 (Wang et al. 2016a). Ma et al. (2018) studied pyrolysis behavior of four types of lignin which were isolated from palm kernel shell with different severities: milled wood lignin (MWL), alkali lignin (AL), Klason lignin (KL), and 
organosolv ethanol lignin (OEL). As the conversion rate increased from 0.1 to 0.8 , the activation energy estimated from DAEM model of KL gradually increased from 170.8 to $580.5 \mathrm{~kJ} \cdot \mathrm{mol}^{-1}$.

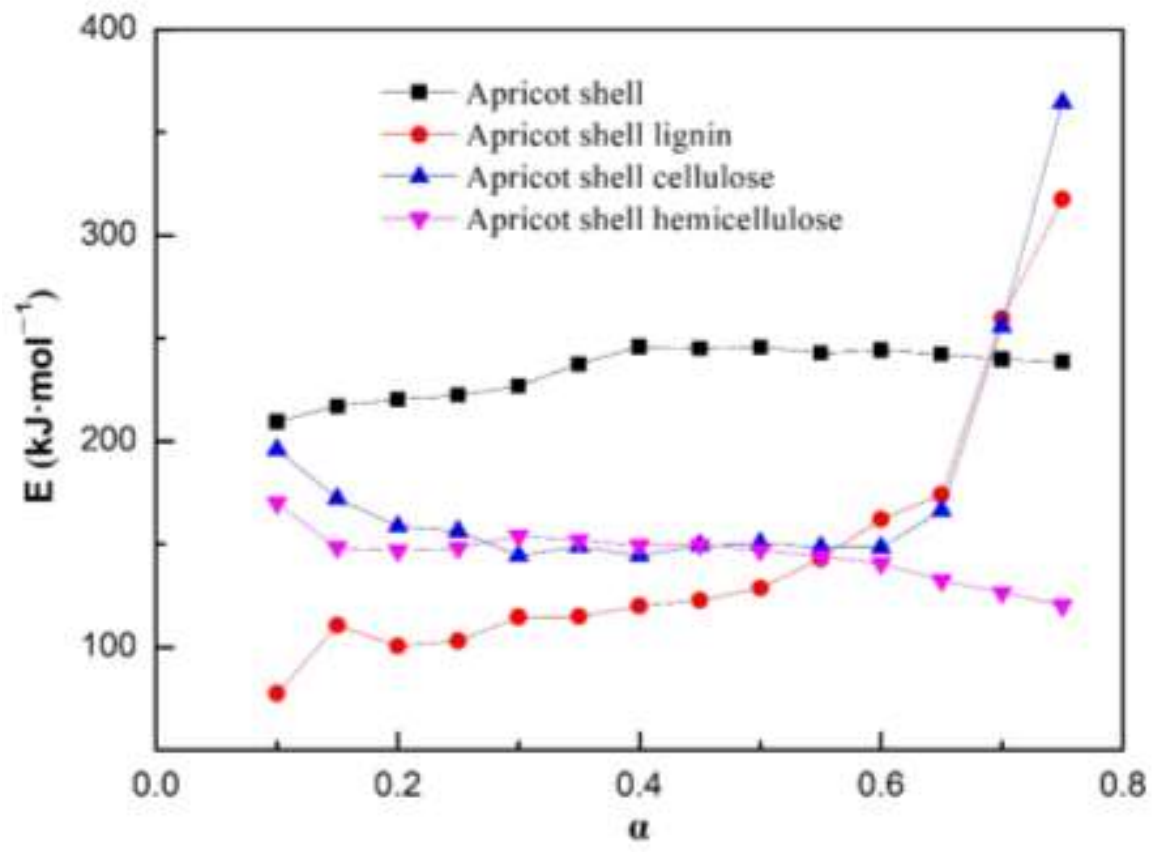

Fig. 6. Relationship of $\alpha$ as a function of $E$ as estimated by the distributed activation energy for the apricot stone, lignin, cellulose, and hemicellulose

As shown in the Fig. 6, the activation energy for the pyrolysis of apricot stone cellulose increased and then decreased with the pyrolysis reaction (Wang et al. 2017). At an $\alpha$ less than 0.45 , the activation energy decreased from $196.0 \mathrm{~kJ} \cdot \mathrm{mol}^{-1}$ to $144.4 \mathrm{~kJ} \cdot \mathrm{mol}^{-1}$ as $\alpha$ increased. At an $\alpha$ greater than 0.45 , the activation energy increased from 149.5 $\mathrm{kJ} \cdot \mathrm{mol}^{-1}$ to the maximum of $364.4 \mathrm{~kJ} \cdot \mathrm{mol}^{-1}$. At an $\alpha$ greater than 0.6 , the activation energy suddenly increased, which was similar to the change trend observed for lignin. The activation energy for the pyrolysis of apricot stone cellulose at an $\alpha$ of 0.75 was greater than those observed for the apricot stone and other components. Cai et al. (2013) investigated the kinetic data of xylan and cellulose fitted to a distributed activation energy model (DAEM) where the activation energies for the pyrolysis of each reactant followed a Gaussian distribution. The activation energy distribution peaks were centered at 178.3 and $210.0 \mathrm{~kJ} \cdot \mathrm{mol}^{-1}$ for xylan and cellulose respectively.

The activation energy for the pyrolysis of apricot stone hemicellulose exhibited a steady downward trend. At an $\alpha$ of less than 0.20 , the activation energy decreased from $171 \mathrm{~kJ} \cdot \mathrm{mol}^{-1}$ to $148 \mathrm{~kJ} \cdot \mathrm{mol}^{-1}$ with the increase of $\alpha$. At an $\alpha$ between 0.20 and 0.35 , the activation energy increased from $148 \mathrm{~kJ} \cdot \mathrm{mol}^{-1}$ to $155 \mathrm{~kJ} \cdot \mathrm{mol}^{-1}$. At an $\alpha$ greater than 0.6 , the activation energy for the pyrolysis of apricot stone hemicellulose was less than those for the apricot stone and other components and then decreased to the lowest value of 120.2 $\mathrm{kJ} \cdot \mathrm{mol}^{-1}$ at an $\alpha$ of 0.75 . Wang et al. (2015) investigated the distribution of activation energy for pyrolysis of hemicellulose polymers isolated from two agricultural straw samples by using a DAEM with a single Gaussian function, and obtained a mean activation energy of $150 \mathrm{~kJ} \cdot \mathrm{mol}^{-1}$. 
From the relationship between the activation energy for the pyrolysis of apricot stone and its components and the reaction conversion rate, $\alpha$ or $E$ corresponded to the pyrolysis temperature. At low pyrolysis temperatures $(400 \mathrm{~K}$ to $600 \mathrm{~K})$, the pyrolysis of hemicellulose was the main pyrolysis reaction. With the continuous increase in the pyrolysis temperature $(600 \mathrm{~K}$ to $660 \mathrm{~K})$, cellulose in the raw material underwent considerable pyrolysis, and its activation energy was relatively high. At the start of pyrolysis, the activation energy for lignin was low, with the widest range of the pyrolysis temperature. In the early stage of pyrolysis, the apparent activation energy for the apricot stone mainly depended on the pyrolysis of hemicellulose and lignin; hence, the activation energy was low. At the later stage of pyrolysis, the apparent activation energy for the apricot stone mainly resulted from the pyrolysis of cellulose and lignin; hence, the activation energy was higher. Ren et al. (2018) studied the thermal oxidative degradation kinetics of peanut shell (PS) and sunflower shell (SS) by using distributed activation energy model (DAEM). The activation energy ranges calculated by the DAEM for the thermal oxidative degradation of PS and SS were 88.9 to $145.3 \mathrm{~kJ} \cdot \mathrm{mol}^{-1}$ and 94.9 to $169.2 \mathrm{~kJ} \cdot \mathrm{mol}^{-1}$, respectively.

\section{CONCLUSIONS}

1. The kinetics of the apricot stone, lignin, cellulose, and hemicellulose pyrolysis were analyzed from thermogravimetric data by the distributed activation energy mode. The correlation coefficient $\mathrm{R}^{2}$ indicated that the mechanism models selected for the kinetics analysis of the apricot stone and its components were reliable.

2. The activation energy for the pyrolysis of the apricot stone was in the range from 209 $\mathrm{kJ} \cdot \mathrm{mol}^{-1}$ to $245 \mathrm{~kJ} \cdot \mathrm{mol}^{-1}$. Lignin exhibited the widest range of activation energy values from $77.4 \mathrm{~kJ} \cdot \mathrm{mol}^{-1}$ to $317.5 \mathrm{~kJ} \cdot \mathrm{mol}^{-1}$. The activation energy for cellulose first decreased from $196.0 \mathrm{~kJ} \cdot \mathrm{mol}^{-1}$ to $144.4 \mathrm{~kJ} \cdot \mathrm{mol}^{-1}$ and increased to the maximum of $364.4 \mathrm{~kJ} \cdot \mathrm{mol}^{-1}$. The activation energy of hemicellulose exhibited a steady downward trend from $171 \mathrm{~kJ} \cdot \mathrm{mol}^{-1}$ to $120.2 \mathrm{~kJ} \cdot \mathrm{mol}^{-1}$.

\section{ACKNOWLEDGMENTS}

This research was financially supported by the National Key R\&D Program of China (2016YFE0201800) and the Priority Academic Program Development (PAPD) of Jiangsu Higher Education Institutions.

\section{REFERENCES CITED}

Ahmad, M. S., Mehmood, M. A., Liu, C.-G., Tawab, A., Bai, F.-W., Sakdaronnarong, C., Xu, J., Rahimuddin, S. A., and Gull, M. (2018). "Bioenergy potential of Wolffia arrhiza appraised through pyrolysis, kinetics, thermodynamics parameters and TGFTIR-MS study of the evolved gases," Bioresource Technology 253, 297-303. DOI: 10.1016/j.biortech.2018.01.033

Akhtar, A., Krepl, V., and Ivanova, T. (2018). "A combined overview of combustion, 
pyrolysis, and gasification of biomass," Energy \& Fuels 32(7), 7294-7318. DOI: 10.1021/acs.energyfuels.8b01678

Ali, I., Naqvi, S. R., and Bahadar, A. (2018). "Kinetic analysis of Botryococcus braunii pyrolysis using model-free and model fitting methods," Fuel 214, 369-380. DOI: 10.1016/j.fuel.2017.11.046

Ali, S., Masud, T., and Abbasi, K. S. (2011). "Physico-chemical characteristics of apricot (Prunus armeniaca L.) grown in Northern areas of Pakistan," Scientia Horticulturae 130(2), 386-392. DOI: 10.1016/j.scienta.2011.05.040

ASTM D1102-84 (2013). "Standard test method for ash in wood," ASTM International, West Conshohocken, PA, USA.

ASTM E871-82 (2013). "Standard test method for moisture analysis of particulate wood fuels," ASTM International, West Conshohocken, PA, USA.

ASTM E872-82(2013). "Standard test method for volatile matter in the analysis of particulate wood fuels," ASTM International, West Conshohocken, PA, USA.

Bartocci, P., Tschentscher, R., Stensrød, R. E., Barbanera, M., and Fantozzi, F. (2019). "Kinetic analysis of digestate slow pyrolysis with the application of the master-plots method and independent parallel reactions scheme," Molecules, 24 (9), Article Number 1657. DOI: 10.3390/molecules24091657

Bhagavatula, A., Shah, N., and Honaker, R. (2016). "Estimating the pyrolysis kinetic parameters of coal, biomass, and their blends: A comparative study," Energy \& Fuels 30(12), 10045-10054. DOI: 10.1021/acs.energyfuels.5b00692

Burhenne, L., Messmer, J., Aicher, T., and Laborie, M.-P. (2013). "The effect of the biomass components lignin, cellulose and hemicellulose on TGA and fixed bed pyrolysis," Journal of Analytical and Applied Pyrolysis 101, 177-184. DOI: 10.1016/j.jaap.2013.01.012

Cai, J., Wu, W., and Liu, R. (2014). "An overview of distributed activation energy model and its application in the pyrolysis of lignocellulosic biomass," Renewable and Sustainable Energy Reviews 36, 236-246. DOI: 10.1016/j.rser.2014.04.052

Cai, J., Wu, W., Liu, R., and Huber, G. W. (2013). "A distributed activation energy model for the pyrolysis of lignocellulosic biomass," Green Chemistry 15(5), 13311340. DOI: $10.1039 / \mathrm{c} 3 \mathrm{gc} 36958 \mathrm{~g}$

Chen, D., Zhou, J., and Zhang, Q. (2014). "Effects of heating rate on slow pyrolysis behavior, kinetic parameters and products properties of moso bamboo," Bioresource Technology 169, 313-319. DOI: 10.1016/j.biortech.2014.07.009

Coimbra, R. N., Escapa, C., and Otero, M. (2019). "Comparative thermogravimetric assessment on the combustion of coal, microalgae biomass and their blend," Energies 12(15), Article Number 2962. DOI: 10.3390/en12152962

Corbett, D., Kohan, N., Machado, G., Jing, C., Nagardeolekar, A., and Bujanovic, B. (2015). "Chemical composition of apricot pit shells and effect of hot-water extraction," Energies 8(9), 9640-9654. DOI: 10.3390/en8099640

Damartzis, T., Vamvuka, D., Sfakiotakis, S., and Zabaniotou, A. (2011). "Thermal degradation studies and kinetic modeling of cardoon (Cynara cardunculus) pyrolysis using thermogravimetric analysis (TGA)," Bioresource Technology 102(10), 62306238. DOI: 10.1016/j.biortech.2011.02.060

De Caprariis, B., Santarelli, M. L., Scarsella, M., Herce, C., Verdone, N., and De Filippis, P. (2015). "Kinetic analysis of biomass pyrolysis using a double distributed activation energy model," Journal of Thermal Analysis and Calorimetry 121(3), 1403-1410.

DOI: $10.1007 / \mathrm{s} 10973-015-4665-2$ 
Demiral, I., and Kul, Ş. Ç. (2014). "Pyrolysis of apricot kernel shell in a fixed-bed reactor: Characterization of bio-oil and char," Journal of Analytical and Applied Pyrolysis 107, 17-24. DOI: 10.1016/j.jaap.2014.01.019

Dorez, G., Ferry, L., Sonnier, R., Taguet, A., and Lopez-Cuesta, J.-M. (2014). "Effect of cellulose, hemicellulose and lignin contents on pyrolysis and combustion of natural fibers," Journal of Analytical and Applied Pyrolysis 107, 323-331. DOI: 10.1016/j.jaap.2014.03.017

Gaurav, N., Sivasankari, S., Kiran, G. S., Ninawe, A., and Selvin, J. (2017). "Utilization of bioresources for sustainable biofuels: A review," Renewable and Sustainable Energy Reviews 73, 205-214. DOI: 10.1016/j.rser.2017.01.070

Hu, M., Chen, Z., Wang, S., Guo, D., Ma, C., Zhou, Y., Chen, J., Laghari, M., Fazal, S., Xiao, B., et al. (2016). "Thermogravimetric kinetics of lignocellulosic biomass slow pyrolysis using distributed activation energy model, Fraser-Suzuki deconvolution, and iso-conversional method," Energy Conversion and Management 118, 1-11. DOI: 10.1016/j.enconman.2016.03.058

Jia, H., Wang, Y., and Xu, G. (2013). "Study on optimization of activated carbon preparation process based on apricot shell," Advanced Materials Research 785-786, 739-744. DOI: 10.4028/www.scientific.net/AMR.785-786.739

Jiang, G., Nowakowski, D. J., and Bridgwater, A. V. (2010). "A systematic study of the kinetics of lignin pyrolysis," Thermochimica Acta 498(1-2), 61-66. DOI: 10.1016/j.tca.2009.10.003

Li, W., Yang, K., Peng, J., Zhang, L., Guo, S., and Xia, H. (2008). "Effects of carbonization temperatures on characteristics of porosity in coconut shell chars and activated carbons derived from carbonized coconut shell chars," Industrial Crops and Products 28(2), 190-198. DOI: 10.1016/j.indcrop.2008.02.012

Li, Z., Han, C., and Gu, T. (2018). "Economics of biomass gasification: A review of the current status," Energy Sources, Part B: Economics, Planning, and Policy 13(2), 137140. DOI: $10.1080 / 15567249.2017 .1410593$

Lin, Y., Chen, Z., Dai, M., Fang, S., Liao, Y., Yu, Z., and Ma, X. (2018). "Co-pyrolysis kinetics of sewage sludge and bagasse using multiple normal distributed activation energy model (M-DAEM)," Bioresource Technology 259, 173-180. DOI: 10.1016/j.biortech.2018.03.036

Ma, Z., Chen, D., Gu, J., Bao, B., and Zhang, Q. (2015). "Determination of pyrolysis characteristics and kinetics of palm kernel shell using TGA-FTIR and model-free integral methods," Energy Conversion and Management 89, 251-259. DOI: 10.1016/j.enconman.2014.09.074

Ma, Z., Wang, J., Zhou, H., Zhang, Y., Yang, Y., Liu, X., Ye, J., Chen, D., and Wang, S. (2018). "Relationship of thermal degradation behavior and chemical structure of lignin isolated from palm kernel shell under different process severities," Fuel Processing Technology 181, 142-156. DOI:10.1016/j.fuproc.2018.09.020

Marzbali, M. H., Esmaieli, M., Abolghasemi, H., and Marzbali, M. H. (2016). "Tetracycline adsorption by $\mathrm{H}_{3} \mathrm{PO}_{4}$-activated carbon produced from apricot nut shells: A batch study," Process Safety and Environmental Protection 102, 700-709. DOI: 10.1016/j.psep.2016.05.025

Ranzi, E., Cuoci, A., Faravelli, T., Frassoldati, A., Migliavacca, G., Pierucci, S., and Sommariva, S. (2008). "Chemical kinetics of biomass pyrolysis," Energy \& Fuels 22(6), 4292-4300. DOI: 10.1021/ef800551t

Ren, X., Chen, J., Li, G., Wang, Y., Lang, X., and Fan, S. (2018). "Thermal oxidative 
degradation kinetics of agricultural residues using distributed activation energy model and global kinetic model," Bioresource Technology 261, 403-411. DOI:

10.1016/j.biortech.2018.04.047

Saikia, R., Baruah, B., Kalita, D., Pant, K. K., Gogoi, N., and Kataki, R. (2018).

"Pyrolysis and kinetic analyses of a perennial grass (Saccharum ravannae L.) from north-east India: Optimization through response surface methodology and product characterization," Bioresource Technology 253, 304-314. DOI: 10.1016/j.biortech.2018.01.054

Shen, D. K., Gu, S., and Bridgwater, A. V. (2010a). "The thermal performance of the polysaccharides extracted from hardwood: Cellulose and hemicellulose," Carbohydrate Polymers 82(1), 39-45. DOI: 10.1016/j.carbpol.2010.04.018

Shen, D. K., Gu, S., Luo, K. H., Wang, S. R., and Fang, M. X. (2010b). "The pyrolytic degradation of wood-derived lignin from pulping process," Bioresource Technology 101(15), 6136-6146. DOI: 10.1016/j.biortech.2010.02.078

Shen, D. K., Gu, S., Jin, B., and Fang, M. X. (2011). "Thermal degradation mechanisms of wood under inert and oxidative environments using DAEM methods," Bioresource Technology 102(2), 2047-2052. DOI: 10.1016/j.biortech.2010.09.081

Slopiecka, K., Bartocci, P., and Fantozzi, F. (2012). "Thermogravimetric analysis and kinetic study of poplar wood pyrolysis," Applied Energy 97, 491-497. DOI: 10.1016/j.apenergy.2011.12.056

Song, E., Kim, D., Jeong, C.-J., and Kim, D.-Y. (2019). "A kinetic study on combustible coastal debris pyrolysis via thermogravimetric analysis," Energies 12(5), Article Number 836. DOI: 10.3390/en12050836

Soni, B., Hassan, E. B., and Mahmoud, B. (2015). "Chemical isolation and characterization of different cellulose nanofibers from cotton stalks," Carbohydrate Polymers 134, 581-589. DOI: 10.1016/j.carbpol.2015.08.031

Stefanidis, S. D., Kalogiannis, K. G., Iliopoulou, E. F., Michailof, C. M., Pilavachi, P. A., and Lappas, A. A. (2014). "A study of lignocellulosic biomass pyrolysis via the pyrolysis of cellulose, hemicellulose and lignin," Journal of Analytical and Applied Pyrolysis 105, 143-150. DOI: 10.1016/j.jaap.2013.10.013

Tan, F. F., Tang, K. L., Zhang, P., Guo, Y.-J., Qu, M., and Li, Y. (2019). "Utilization of a hydrogen source from renewable lignocellulosic biomass for hydrogenation of nitroarenes," ChemCatChem 11(16), 4189-4195. DOI: 10.1002/cctc.201900087

TAPPI T222 (2002). "Acid-insoluble lignin in wood and pulp," Technical Association of the Pulp and Paper Industry, Atlanta, GA, USA.

Usman, M., Chen, H., Chen, K., Ren, S., Clark, J. H., Fan, J., Luo, G., and Zhang, S. (2019). "Characterization and utilization of aqueous products from hydrothermal conversion of biomass for bio-oil and hydro-char production: A review," Green Chemistry 21(7), 1553-1572. DOI: 10.1039/C8GC03957G

Vand, V. (1943). "A theory of the irreversible electrical resistance changes of metallic films evaporated in vacuum," Proceedings of the Physical Society 55(3), 222-246. DOI: $10.1088 / 0959-5309 / 55 / 3 / 308$

Viottoa, R. S., Maia, A. A. D., Yamaji, F. M., and De Morais, L. C. (2018). "Thermogravimetric investigation of spent shiitake substrate to solid biofuel," Canadian Journal of Chemical Engineering 96(4), 845-854.

DOI: $10.1002 /$ cjce. 23026

Wang, J., Zhang, S., Guo, X., Dong, A., Chen, C., Xiong, S., Fang, Y., and Yin, W. (2012). "Thermal behaviors and kinetics of pingshuo coal/biomass blends during 
copyrolysis and cocombustion," Energy \& Fuels 26(12), 7120-7126. DOI:

10.1021/ef301473k

Wang, S., Dai, G., Ru, B., Zhao, Y., Wang, X., Xiao, G., and Luo, Z. (2017). "Influence

of torrefaction on the characteristics and pyrolysis behavior of cellulose," Energy 120, 864-871. DOI: 10.1016/j.energy.2016.11.135

Wang, S., Lin, H., Ru, B., Dai, G., Wang, X., Xiao, G., and Luo, Z. (2016a). "Kinetic modeling of biomass components pyrolysis using a sequential and coupling method," Fuel 185, 763-771. DOI: 10.1016/j.fuel.2016.08.037

Wang, S., Lin, H., Zhang, L., Dai, G., Zhao, Y., Wang, X., and Ru, B. (2016b).

"Structural characterization and pyrolysis behavior of cellulose and hemicellulose isolated from softwood Pinus armandii franch," Energy \& Fuels 30(7), 5721-5728. DOI: 10.1021/acs.energyfuels.6b00650

Wang, S., Ru, B., Lin, H., Dai, G., Wang, Y., and Luo, Z. (2016c). "Kinetic study on pyrolysis of biomass components: A critical review," Current Organic Chemistry 20(23), 2489-2513. DOI: 10.2174/1385272820666160525115832

Wang, S., Ru, B., Dai, G., Sun, W., Qiu, K., and Zhou, J. (2015). "Pyrolysis mechanism study of minimally damaged hemicellulose polymers isolated from agricultural waste straw samples," Bioresource Technology 190, 211-218. DOI: 10.1016/j.biortech.2015.04.098

Wang, W., Li, X., Dan, Y., Cai, L., and Shi, S. Q. (2018). "Catalytic pyrolysis of larch sawdust for phenol-rich bio-oil using different catalysts," Renewable Energy 121, 146-152. DOI: 10.1016/j.renene.2018.01.018

Xu, L., Guo, F., Wang, G., Giesy, J. P., Bai, Y., Wang, X., and Song, F. (2019). "Correlations between slow pyrolysis characteristics and organic carbon structure of aquatic plant biomass," Environmental Science and Pollution Research 26(17), 17555-17566. DOI: 10.1007/s11356-019-04936-2

Yan, Y., Meng, Y., Tang, L., Kostas, E. T., Lester, E. H., Wu, T., and Pang, C. H. (2019). "Ignition and kinetic studies: The influence of lignin on biomass combustion," Energy \& Fuels 33(7), 6463-6472. DOI: 10.1021/acs.energyfuels.9b01089

Yang, H., Yan, R., Chen, H., Lee, D. H., and Zheng, C. (2007). "Characteristics of hemicellulose, cellulose and lignin pyrolysis," Fuel 86(12-13), 1781-1788. DOI: 10.1016/j.fuel.2006.12.013

Yang, K., Gao, Q., Tan, Y., Tian, W., Zhu, L., and Yang, C. (2015). "Microporous carbon derived from Apricot shell as cathode material for lithium-sulfur battery," Microporous and Mesoporous Materials 204, 235-241. DOI: 10.1016/j.micromeso.2014.12.003

Zhang, J., Chen, T., Wu, J., and Wu, J. (2014). "A novel Gaussian-DAEM-reaction model for the pyrolysis of cellulose, hemicellulose and lignin," RSC Advances 4(34), 17513-17520. DOI: 10.1039/C4RA01445F

Zhou, Z., Lei, F., Li, P., and Jiang, J. (2018). "Lignocellulosic biomass to biofuels and biochemicals: A comprehensive review with a focus on ethanol organosolv pretreatment technology," Biotechnology and Bioengineering 115(11), 2683-2702. DOI: 10.1002/bit.26788

Article submitted: September 16, 2019; Peer review completed: November 17, 2019; Revised version received and accepted: December 16, 2019; Published: January 6, 2020. DOI: 10.15376/biores.15.1.1187-1204 